\title{
Aboriginal identity, world views, research and the story of the Burra'gorang
}

\section{Gawaian Bodkin-Andrews, Aunty Frances Bodkin, Uncle Gavin Andrews and Uncle Ross Evans}

\section{Introduction}

N RECENT TIMES there has been a growing recognition that some Aboriginal and

Torres Strait Islander peoples and communities have been harmed and even divided by those who question their very right to identify as 'Indigenous or not' (Bodkin-Andrews \& Carlson 2016; New South Wales Aboriginal Education Consultative Group [NSW AECG] 2011). Numerous scholars have suggested that such 'questions' are an unfortunate extension of the continual epistemological violence (a pressure on ways of knowing) that has sought to eradicate the diverse world views, histories, and knowledges of our peoples since colonisation (Bodkin 2013a; Moreton-Robinson 2011; Nakata 2012), and that they result in the emergence of stereotypical accusations of 'inauthenticity', 'wanna-be-Aborigines', 'welfare-blacks', 'fragmentation' and 'cultural absurdity' (Behrendt 2006). It is the purpose of this chapter to highlight the existence of this form of epistemological and identity-based violence and explain how it threatens our communities. In addition, such violence will be challenged by focusing on the strength of diverse world views, knowledges and unique stories that exist within Aboriginal and Torres Strait Islander communities today. We also offer you a traditional D'harawal Law Story as the central case study within this chapter. This Law Story holds valuable insights that may guide individuals and communities towards a stronger and more resilient future.

\section{D'hawaral positioning}

Many respected Indigenous scholars have argued that it is critical that people who seek to work within Aboriginal communities be aware of, and transparent about, their own ways of knowing, and how this may bias their learning and actions (Foley 
2003; Linklater 2014; Kovach 2009; Rigney 1999; Smith 2012). As a result, it should be understood that this chapter is written through a lens shared by the authors. This lens emanates from clans within the D'harawal nation or language group located in south-west Sydney, Australia. In our own ways, we have each struggled against the longstanding and continuing impact of colonisation, ranging from popular media misinformation to our location, learnings, stories and oral histories being contested by quasi-anthropological works relying on, and selectively ignoring, conflicting evidence from the diaries and scribblings of the early colonisers (cf. Kohen 1993). Despite family histories of dislocation and imposed reserve life, Stolen Generations, and forced denial of identity, we have retained and maintained our cultural values and Creation and Law Stories that are integral to our strong sense of kinship today.

By engaging with the works of respected Indigenous scholars and the traditional D'harawal Law Story of the 'Burra'gorang' ('Giant Kangaroo'), we invite you to embark on an intellectual quest to identify some of the learnings within this story that, in part, parallel the identity violence that Aboriginal and Torres Strait Islander communities are forced to endure today. We share this story because within the D'harawal context, storytelling is one of our most important methods of communication, learning, and promoting mutual respect and understanding (Bodkin 2013b). This story offers insights into our traditional philosophies and we challenge you to attempt to discover some of its layers of meaning. We also hope that you understand that the knowledges shared here are as much for our community, and our future generations, as it is for yours.

\section{CASE STUDY}

\section{The story of the Burra'gorang}

It is known that many of our ancestors lived in times of great prosperity and peace, when the lands provided for The Peoples in abundance, and in return The Peoples cared for the lands, and cared for each other. But The Peoples also have many stories of times of darkness, famine and suffering. Yet, it is within these times of suffering that some of the greatest learnings occurred. This is a story of such suffering $-\mathrm{a}$ story of a monster who fed on the very lives of The Peoples, a monster whose power spread fear and hate through all. This is the story of the Burra'gorang.

\section{REFLECTIVE QUESTION}

Can you think of other stories, Indigenous or non-Indigenous, that have guided the intellectual and moral growth of various groups and cultures today? 


\section{The silencing of Indigenous standpoints}

It can easily be observed that the vast majority of research and policy attempting to address Aboriginal and Torres Strait Islander affairs has placed our peoples and communities in a position of 'otherness'. We are simply passive objects to be studied from Western perspectives that have invaded and attempted to dominate our peoples since the first wave of colonisation that began on January 1788. As the respected Noonuccal scholar Karen Martin has argued, the representation of 'Aboriginal agency is somewhat simplified because it is theorised and constructed in terms of race relations and it is the non-Aboriginal agency that is inevitably centred' (Martin 2008, p. 50). In other words, attempts to understand Aboriginal and Torres Strait Islander peoples and communities have too often been limited by stereotypical Western ways of knowing that fail to grasp the complexity of Aboriginal and Torres Strait Islander ontology (ways of being), axiology (ways of doing) and epistemologies (ways of knowing) (Moreton-Robinson 2011; Rigney 1999; Walter \& Andersen 2013).

It contrast, we recognise that diverse Indigenous world views and knowledge systems have developed and continually evolved over an immeasurable number of generations, despite the recent yet powerful forces of colonisation that have intentionally and unintentionally attempted to suppress and eradicate such knowledges (Bodkin 2013a; Bodkin-Andrews \& Carlson 2016; Walter \& Andersen 2013). We must recognise and understand previous and continuing threats to the very existence of our knowledges, and the emerging threats that may continue this colonial tradition towards cultural genocide. It is critical that all people seeking to understand 'Indigenous Australia' recognise, respect and incorporate perspectives emerging from not only Indigenous scholars, but Aboriginal and Torres Strait Islander communities themselves.

One of the most critical junctures in current debates surrounding 'Indigenous' affairs is that of who can identify as being 'Indigenous' or 'Aboriginal Australian'. Bodkin-Andrews and Carlson (2016) suggest that this debate has emerged from the very foundations of epistemological racism (the overreliance on the misrepresentative lens of social and historical perspectives drawn from the dominant race within any society). This simply serves to further legitimise non-Indigenous researchers' (and politicians') opinions and domination over Aboriginal and Torres Strait Islander peoples and communities, especially concerning their sense of identity (BodkinAndrews \& Carlson 2016; Kickett-Tucker 2009; Rigney 1999; Trudgett \& Page 2014). Sadly, an increasing number of Aboriginal and Torres Strait Islander peoples and scholars have become so embroiled in this debate that they have arguably begun to contribute to the identity violence against Indigenous peoples and their identities (cf. Dillon 2013; Price \& Price 2013). 


\section{Case study continued}

He ran, he ran for his parents, his brothers and sisters, his Aunties and Uncles, and for all of his clan, but most of all, he ran for his life. Marraigang, the Tiger Quoll, ran with the echo of his mother's scream pushing him further and further away from his people; away from the Burra'gorang. Even though his family had thought they were safe hunting in the safety of darkness, Marraigang now fled.

He remembered creeping with well-practiced silence through the dianella plants, while his Uncle, the greatest of their hunters, perched in the branches of a nearby eucalyptus tree, carefully watching over his clan. Yet as Marraigang admired his Uncle, his heart froze as a thunderous roar shook the very trees and shrubs around him. And suddenly his uncle was flying helplessly through the air as the tree he was perched upon exploded at its base and began to plummet towards Marraigang.

Marraigang curled into a tight ball as the heavy branches speared the ground around him. Next to him, a stunted moan escaped his brother's lips before it turned into a final gurgle flooded with blood. He heard the high-pitched scream of his mother, simultaneously laced with the agony of loss, fractured by the force of fear and choked by the crushing pressure of the fallen tree pinning her to the ground. Yet she still she screamed, 'Run Marraigang, run for help!'

Marraigang did not question the battle-drawn wisdom of his mother and quickly leaped away. Yet it was the barbed tail of the Burra'gorang that greeted his first jump, sending him into a moment of complete silence and darkness. His impact with the ground though tore him back to consciousness, and a sharp burning ripped into the muscles and bones of his right shoulder. Despite the pain, he found himself running, driven by the blindness of fear.

Eventually, Marraigang felt his exhaustion take over, and numbness spread through his body and mind. So it was at the base of a Sheoak tree, sprawled on a soft bed of fine leaves that memories of his mother reached through his exhausted delirium to whisper 'When lost, find the safety of the Sheoak'. So with a gentle sob, Marraigang passed out ...

\section{REFLECTIVE QUESTION}

Think of labels such as 'European', 'Australian', 'Christian' and 'Muslim'. What do these labels represent and how accurate a descriptor are they?

\section{The emerging (dis)identity}

There are many texts that have highlighted the negative impact of colonisation, and some have likened colonisation to an ongoing war on the existence of Aboriginal and Torres Strait Islander peoples, communities and cultures (Rose 2012). As already suggested, one of the current threats to our sense of individual and community identity can be found in debates that have embraced notions of 'pan-Aboriginality' (Carlson 
2013; Maddison 2013). Within this context, we argue that too often pan-Aboriginality, or the simple representation of 'Aboriginal or not', is a Western epistemological creation that has become the focal point of policy and research at the expense of any attempt to understand the diversities within and across our many Aboriginal and Torres Strait Islander nations and communities.

A number of studies have emerged within south-west Sydney regions that have, in part, claimed to focus on the sense of identity of Aboriginal and Torres Strait Islander peoples. However, we feel these studies simply contribute to the Western epistemological violence surrounding Indigenous identities and cultures. For example, examining the work of Yamanouchi (2012), who, through qualitative interviews, claimed to investigate the dynamic nature of Aboriginal identity, we observe that Yamanouchi's writings rarely moved beyond broad notions of kinship, blood relations and the controversy of 'wannabe' Aboriginals. Cowlishaw (2012), in one of her two ethnographic observations, reiterated Yamanouchi's findings by suggesting that community-based perceptions of south-west Sydney Aboriginal communities largely hold that much of the traditional culture and practices of the area have been lost. In addition, some scholars (e.g. Everett 2010) have even questioned directly or indirectly the existence of currently named Aboriginal nations prior to colonisation. Finally, while Cowlishaw (2012) highlighted attempts at Aboriginal cultural revivalism within south-west Sydney, her article suggested that such efforts bordered on absurdity. The implication was that the cultural practices being (re)taught in schools (in this case the totemic system) may have been out of place and country, and thus not culturally valid for the Aboriginal communities of south-west Sydney. While such critiques are important (cf. McRae 2006), there were no suggestions of what might be culturally valid. Instead what was taught to young primary school children was simply dismissed as 'anthropologically embarrassing' (Cowlishaw 2012, p. 412). It may be argued that these works downplay and misrepresent the surviving cultural knowledges and practices within south-west Sydney (largely incorporating the D'harawal, Dharug and Gandangarra nations).

Our criticisms of the reasoning of Cowlishaw (2012) and Yamanouchi (2012) may be viewed as exaggerated, given that both claim to capture the Aboriginal voices within the communities they studied. However, we argue that these voices may have been selected for their adherence to the authors' predisposed drive for investigating Aboriginality (or not), as opposed to more complex understandings of identity driven from the foundation of Aboriginal epistemologies (see Kickett-Tucker 2009 for a strong example of this). In either case, the value of this research in its ability to either support or strengthen the Aboriginal communities that were the 'objects' of the scholarly attention can be questioned. 
A recent report commissioned by a strong Aboriginal education governance body has also investigated Aboriginality and identity within New South Wales (NSW AECG 2011), and has produced similar findings to that of Yamanouchi (2012) and Cowlishaw (2012). While the NSW AECG report did well to highlight that the label 'Aboriginal' was essentially a colonial construct, its focus moved to an emphasis on the three-point definition of Aboriginality included within the Aboriginal Land Rights Act 1983 (NSW). Namely, an 'Aboriginal person means a person who (a) is a member of the Aboriginal race of Australia, and (b) identifies as an Aboriginal person, and (c) is accepted by the Aboriginal community as an Aboriginal person' (NSW AECG 2011, p. 13). Although the report claimed to investigate the complexities of Aboriginal identity within the New South Wales context, the themes that emerged from Aboriginal community consultations were limited to opinions on the above-mentioned definition. Indeed, one of the strongest themes to emerge was an emphasis on increasing concern with regards to occurrences of fraudulent claims of Aboriginality (NSW AECG 2011).

While it is important to acknowledge the strength of these community frustrations, such perceptions may be a symptom of forced Western epistemological reasoning that spread through our communities as a form of internalised identity violence. First, as argued by a number of Aboriginal and Torres Strait Islander scholars (e.g. Bodkin-Andrews \& Carlson 2016; Moreton-Robinson 2011; Nakata 2012), such debates emanate from a deficit discourse where definitions of Aboriginality are solely centred on welfare and disadvantage. Second, research examining the extent of fraudulent claims is largely non-existent, or indirect and anecdotal in nature, where broad statistics (e.g. population growth of Aboriginal Australians) are argued to be direct 'evidence' for fraudulence, despite no direct measure (e.g. Johns 2011). Finally, the authenticity debate may be argued to be an imposed form of lateral violence that is now being perpetuated within our own communities (Gorringe, Ross \& Fforde 2011).

Unfortunately, popular media has long propagated the dichotomous Aboriginality debate, particularly at the expense of Indigenous peoples who do not fit images that are often associated with disadvantage and poverty (Carlson 2013; Nakata 2012). Emerging from this debate, some Aboriginal representatives have been celebrated for embracing similar discourses. For example, Price and Price (2013) attempted to disregard the knowledges of Aboriginal people 'who live in the suburbs' as little more than academic 'musings' and 'faded memories' when they argued that 'unless they have studied anthropology and linguistics [authors' note: Western epistemological justifications], their understanding of traditional law and culture will come from the half remembered musings of aged relatives, themselves several generations removed from traditional life' (p. 193). Dillon (2013) has been another Aboriginal scholar who has repeatedly voiced scepticism about the rights of Aboriginal people 
to identify with their cultures, especially in the face of racism. He suggests that the Aboriginal Australians who tend to be most vocal in the fight against racism and for social justice are 'typically those with the least Aboriginal ancestry' (p. 89). In doing so not only does Dillon reject the rights of some Aboriginal people to identify with their nations based on an outdated blood-quota mentality, but he later argues that Aboriginal people should unite with non-Aboriginal Australians as 'one people' by focusing on our similarities as opposed to respecting our differences. Such arguments are supported by assimilationists such as Johns (2011), who has repeatedly suggested that Aboriginal people should leave their culture in the past.

The above arguments, we feel, will ultimately contribute to the eradication of our diverse cultures and distinct knowledges, for in the powerful words of MoretonRobinson (2011), the imposed assimilative understanding of "'Aboriginality" violates our subjectivity by obliterating any trace of our different ontological and epistemological existences ...' (p. 414).

\section{Case study continued}

Shadows seemed to dance behind Marraigang's closed eyelids as he suddenly became aware of not only his pain but another presence. With resignation, Marraigang opened his eyes to see a figure standing before him. 'What are you doing here boy?' It was the deep voice of Mananga, the Wedge Tailed Eagle, which Marraigang heard.

'Yes boy, this is not your territory, what right do you have to be here?' To his left, the sing-song voice of Didjiri, the Willy-Wagtail, was laced with suspicion.

Marraigang tried to stand, but the powerful talons of Mananga painfully griped his injured shoulder, almost overwhelming him again. 'Answer the question boy or I will tear what's left of your shoulder apart!'

'Arrgghh!' Marraigang screamed. 'I was running. R-running ... from ... the Burra'gorang.'

'What?!' Didjiri sprung forward. 'So you thought to lead it here, to our peoples!'

Marraigang was confused at the accusation. 'Wh-What do you mean ... I didn't know where I was going ...' In a softer voice he whispered, 'I don't even know if my family are alive.'

Mananga too leaned forward, putting even more pressure on Marraigang's shoulder. 'Boy, do you honestly think we care about your family when you put ours at risk? I would leave your carcass here to appease the Burra'gorang, but I feel you'd only begin to whet its appetite.'

Didjiri scoffed and then said, 'We need to take this traitor to our Elders for punishment.'

Mananga nodded his head, and with little care or sensitivity to Marraigang's wounds, dragged him back to their campsite, dropping him before the resting place of their Elders. 
Wiritjiribin, the Lyrebird, the oldest and most respected within the clan, looked down at Marraigang with impassive yet probing eyes. 'It has been a long time since we have had a visitor, why did you bring one here from another clan, Mananga? Especially considering it seems without their will?'

Didjiri instead responded, 'He was trespassing on our lands Aunty and admitted himself to leading the Burra'gorang here!'

'Ah yes, an accusation I've heard from your lips many times Didjiri,' Wiritjiribin replied. 'You are a brave warrior, but sometimes I fear war is all you think of.' Didjiri bristled at the reprimand, but bowed his head in acquiescence. 'What is your story Mananga?' Wiritjiribin asked.

Mananga looked down at the cowering form of Marraigang and nearly spat out his words. 'He was asleep under a Sheoak when we found him and obviously injured from his foolish mission. He pretended that he could make no sense of where he was, but he is on our lands without permission.'

Wiritjiribin leaned forward to glare at Mananga. 'There was a time when our ancestors need not care for 'ours' and 'their' lands... It is sad how we have changed.'

A second Elder, Yuranyi the Black Duck, spoke up. 'But Mananga is right, he is far away from his clan and should be punished.'

Wiritjiribin though slowly shook her head. 'I have a feeling he may have already been punished enough.' Again looking into Marraigang's eyes, Wiritjiribin now asked, 'So child, what really brings you here?'

Marraigang saw neither comfort nor judgement in the eyes of Wiritjiribin, so with a calm voice he retold of what had just torn his life apart. The Elders and a number of other warriors sat in to listen patiently. He told of his pain, and the loss of his loved ones, and stopped his story at passing out under the Sheoak tree.

Mananga and Didjiri glanced at each other, knowing he could have told of the pain they had inflicted upon him, but did not ...

\section{REFLECTIVE QUESTION}

Attempt to identify the many reasons as to why some Aboriginal and Torres Strait Islander peoples may have no knowledge of or have abandoned their sense of identity. What impact could this have on their acceptance by the Indigenous community?

\section{Recognising epistemologies and identities}

As already discussed, a significant portion of policy and related academic research attempting to understand the nature and impact of Aboriginal identity is largely limited to dichotomous labels of Aboriginality (Aboriginal or not). On occasion, some research has focused on more general cognitive/affective measures (e.g. feels good to be Aboriginal) also popular within the Western international context, without 
exploring the more in-depth meanings of identity (e.g. Bodkin-Andrews, Denson, Finger \& Craven 2013; Purdie, Tripcony, Boulton-Lewis, Fanshawe \& Gunstone 2000). Much of this research, however, has been quantitatively orientated and for the most part produced findings that indicate lack of support for positive outcomes being associated with a stronger sense of identity.

While it may be easy to target the use of quantitative statistics as the reason for this lack of result, we argue that the very Western epistemological underpinning (methodology) of what is decided to be measured in the first place is where the inaccuracies lie (Walter \& Andersen 2013). Consider that Purdie and colleagues' (2000) study also held a strong qualitative component that captured the voices of Aboriginal and Torres Strait Islander students and their understanding of their identities. From these interviews, it was found that their sense of identity was a diverse, multifaceted, contextually sensitive and complicated construct (including themes of kinship, true history, languages, traditional practices and a strong sense of place).

The complexities of Aboriginal identities have been highlighted in a number of other studies, such as Colquhoun and Dockery's (2012) research examining interviews with the parents and caregivers of Aboriginal and Torres Strait Islander children. When asked about the strength of their child's Aboriginal and Torres Strait Islander culture, parents moved beyond broad feel-good statements and emphasised knowledge of their heritage, history, stories and country; use of language; awareness of cultural traditional and protocols; kinship connections; respect for Elders; spirituality; and a strong sense of community belonging. KickettTucker (2009) identified a similar pattern in the diversity of self-perceptions related to meanings of Aboriginality held by Aboriginal children and youth. Specifically, around 30 separate aspects of identity emerged, ranging from broad factors such as pride, self-esteem and sport, to more culturally specific aspects such as traditions, stories, country, language and family.

There is also an increasing research base linking diverse aspects of Aboriginal identities and world views to positive outcomes ranging from individual and community resiliency and empowerment (Bamblett, Harrison \& Lewis 2010), increased social and emotional wellbeing (Zubrick et al. 2005), increased educational engagement and performance (Riley \& Genner 2011) and a stronger sense of environmental responsibility and sustainability (Mercer, Kelman, Taranis \& SuchetPearson 2010). Extending on these strengths, a quantitative study by Dobia et al. (2014) measured nine separate dimensions of Aboriginal identity within a rural community and many were found to be positively related to a wide diversity of outcomes. For example, stronger participation in cultural events and knowledge of Aboriginal stories and history were associated with higher levels of school engagement. In addition, 
students with a stronger sense of community support, participation in cultural events and respect for Aboriginal protocols had a stronger sense of resiliency.

\section{Case study continued}

Wiritjiribin, the Lyrebird, looked among the Elders and warriors of her clan, and saw their eyes lowered and shoulders hunched as yet another story of the atrocities of the Burra'gorang weighed on their spirits. She looked towards Marraigang and softly asked, 'What is it you want, Marraigang?'

Marraigang's reply came immediately. 'My clan is gone. Let me heal and then I will find the Burra'gorang and ...' He paused as if he sensed the foolishness in his words, yet his pain drove his will. 'I will try to kill it.'

Mullgoh the Swan shook her long neck and her eyes flashed with anger. 'And you will die like so many of our warriors before them! Even the Spirit Woman has not answered our calls for help!'

While Wiritjiribin regarded Mullgoh with sadness, the rest of the clan shifted uncomfortably, for they knew how often the Elders called for the Spirit Woman's aid. Yuranyi the Black Duck shuffled with agitation as he muttered, 'Even she fears to stand before the Burra'gorang'.

At those words, Mananga, who had previously sat to consider the weight of both Marraigang's story and the untold pain he had added to it, rose to face Mullgoh and Yuranyi. 'I mean no disrespect, Aunty and Uncle, but we have done little to deserve the Spirit Woman's attention.' Mananga then moved to stand next to Marraigang. 'You have shown me respect when I deserved little. Count me as your brother.'

Gasps and cries of despair rang around the clan. Dharmuoy, the Bronze-Winged Pigeon and youngest warrior of the clan, began to plead, 'Mananga, you are our strongest warrior, we cannot lose you!'

Manganga shook his head. 'There are no warriors if we fail to protect our children and our old ones.'

At these words Wiritjiribin rose from her perch and stood before both Marraigang and Mananga. 'You have shown a courage that has been forgotten, but we must find others who share your strength.'

And so, as Marraigang healed from his wounds, some warriors tracked the Burra'gorang, and watched for its weaknesses. Mananga was given the clan message stick and travelled to other clans to tell them their plans. While many turned their backs in fear, some warriors, once bitter enemies, stepped forth.

\section{REFLECTIVE QUESTION}

Consider the diversity of significant Aboriginal and Torres Strait Islander cultural events, media sources, movies and literary works, and identify how they may contribute to our understanding of Indigenous peoples and communities and their identities today. 


\section{Storytelling, identities and Indigenous research methodologies}

In much research literature embracing Indigenous standpoints, both nationally and internationally, storytelling is valued as an essential element of many First Nations peoples' world views and sense of identity. Storytelling is seen as not only a critical method of sharing knowledges, but also a valuable tool for resistance to and healing from ongoing colonial violence affecting both individuals and communities (Bessarrab \& Ng'andu 2010; Linklater 2014; Martin 2008). Indeed, as explained by the respected Plains Cree and Saulteaux scholar Margaret Kovach:

Stories remind us of who we are and our belonging. Stories hold within them knowledges while simultaneously signifying relationships. In oral tradition, stories can never be decontextualized from the teller. They are active agents within a relational world, pivotal in gaining insight into a phenomenon ... They tie us with our past and provide a basis for continuity with future generations (Kovach 2009, p. 94).

It must be recognised that our stories are not just pre-colonial Law and Creation Stories, but essential stories of survival and resiliency against the onslaught of colonisation, and also powerful stories of strength and growth that exist within many Indigenous communities today. For example, the recent work of Renee Linklater, an Anishinaabe scholar of the Rainy-River First Nations peoples of north-western Ontario, offers an inspiring example of the power of storytelling within contemporary context. Her book Decolonizing Trauma Work (2014) included a collection of stories from a diversity of First Nations health care practitioners who highlighted how they negotiated the interface between Western psychology and psychiatry practices with unique forms of First Nations trauma and healing methods (e.g. addressing historical trauma and racism, sweat lodges, shake tents, community sharing). In doing so, Linklater notes that through the shared stories of the practitioners' life journeys:

their contributions reflect a high degree of cultural and clinical understanding, experience, and wisdom. These practitioners are experts in Indigenous trauma work and utilize strategies that are informed by their experience, worldview and knowledge as Indigenous peoples (2014, p. 72-3).

Within the Australian context, Pat Dudgeon of the Bardi people has suggested that individually orientated Western psychological therapies risk perpetuating homogenous views of Aboriginality as well as overlooking unique cultural strengths that have been found to be linked to Aboriginal people's sense of identity and wellbeing (Dudgeon \& Kelly 2014). While one may consider the imposition of Westernorientated therapies on Aboriginal and Torres Strait Islander peoples as problematic if left unchecked, numerous Aboriginal scholars have begun to commit to yarning 
methods to help use personal and shared stories as a guide for research, policy and practice to strengthen Aboriginal and Torres Strait Islander communities (Bessarab \& Ng'andu 2010; Fredericks et al. 2011; Martin 2008). Yarning as an Indigenous research method seeks to both encapsulate and exchange deeper stories set within an ethos of cultural safety, and as a result has become a powerful tool for healing and resiliency.

A strong example can be found in the work of Fredericks and colleagues (2011) who utilised yarning methods within an Aboriginal organisation to guide workplace smoking policies. Working from a culturally inclusive approach involving the Aboriginal staff, the use of yarning circles to guide policy saw a stronger level of active engagement of the Aboriginal staff, improved peer-to-peer support, increased levels of self-monitoring and a reduction in the need for policing of the policy itself (thus making it sustainable). In the international context, Wexler, White and Trainor (2015) highlighted the power of storytelling within a First Nations community as part of a suicide prevention program. The emphasis was on empowering community support networks to create safe communal settings where stories were shared by local members who spoke of personal experiences of both overcoming suicidal inclinations and helping people at risk of suicide. By sharing these stories, the community become empowered not only to act against the immediate risk of suicide, but also to ensure their stories survived, thus making the support networks sustainable over time.

We hope these two brief examples of contemporary storytelling initiatives offer you insights into the potential strengths within our local communities and organisations. While we have argued that Aboriginal and Torres Strait Islander peoples may be sitting at a precipice overlooking the unconditional acceptance of colonial representations of who we are as 'Indigenous Australians' and how we should be as 'one people', embracing the true pursuit of Indigenous standpoints, and our stories, may protect the very strengths within our diversities.

Too often our traditional world views, knowledges and practices have been alienated, ostracised, oppressed and even destroyed in both early colonial times, and also today by both Aboriginal and non-Aboriginal people. Too often varying legislative initiatives, policies and research designed to 'help' Indigenous people has turned our people against ourselves, our very histories and ways of being (Behrendt \& Kelly 2008). According to Price and Price (2013), we can now only 'authenticate' our epistemologies through white anthropological discourses that rely on 'evidence' limited to the early musings of the colonial oppressors themselves. Alternatively, we simply resign ourselves to wallow in a cultural graveyard littered with Westernorientated headstones venerating the dichotomy of Indigeneity (whether a person is Indigenous or not). In either case, we have ceded control over who we truly are. Our alternative is to embrace and respect our diverse voices, world views, knowledges and 
identities within our communities. To do this we must respect, embrace and pass on our stories, whether they be our Traditional Law Stories, or contemporary stories of survival and healing, or both. We must not rely solely on the Western stories that have been created about us (but not for us), for, as Baskin (2005) argues:

Of course there is no one Aboriginal voice. Rather, there are many. Each of us is a storyteller and each a listener. Together, we are the voices of Aboriginal peoples. Knowledge is passed on by these voices through our oral tradition - our storytelling. Without storytellers and listeners, there would be no culture (p. 181).

\section{Case study continued}

When Marraigang was finally healed, he was greeted by a small army of Peoples he had never seen before. Leading them, Mananga stepped forward to embrace Marraigang warmly. 'I am glad to see you are well brother.' Gesturing behind him, he said, 'These are the warriors who have joined us'.

First Wumbat and Barrugin the Echidna stepped forward. 'We may not be fast, but we are strong, and we can dig.' Next, the Bull Ant spoke. 'I am Wugatjin, and although I see my traditional enemies before me, my bite will instead be aimed at the Burra'gorang.' Nodding his head the Pouched Cat stepped forward. 'I am Daruwa, my teeth are sharp and my bite is also strong, as are my claws. Know that I will fight with you, and that my clan are also looking after your mother and surviving family, know that they are safe.' Marraigang's eyes swelled with tears at this news. Mun'dah, the shy Red-bellied Black Snake, slid forward and whispered, 'Know that I am now your sister, and my speed will help us defeat the Burra'gorang'. And many more warriors stepped forth, each declaring their unity, and each explaining their unique strengths.

So it was Mananga and Marraigang, that led the war-band stealthily through the bush until they found where Dharamuoy had hidden to spy on the Burra'gorang. 'It is time. Our Elders have travelled to the place of the white waratah, and will again ask for the Spirit Woman's help. But we must not wait for the Burra'gorang has just fed, and this is when it sleeps.'

Wumbat and Barrugin quickly set out to the base of a nearby valley to dig a series of tunnel traps, while Dharamuoy and Didjiri gathered a wide array of branches and placed them along the valley walls. Others hid carefully among varying crevices and ledges throughout the small valley, and waited with icy fingers, fear and expectation dancing down their spines.

Just as the sun began its slow trek towards the horizon, Marraigang and Mananga attacked the sleeping Burra'gorang. Marraigang first sunk his teeth into the soft flesh underneath the Burra'gorang's talons, and Mananga then swooped down and raked his talons behind the Burra'gorang's ears.

While the attacks did little damage, the Burra'gorang became enraged and stumbled after Marraigang as he fled into the small valley. Quickly Didjiri joined Mananga's continued attacks by darting around Burra'gorang's head, further disorientating the monster and keeping it a safe distance from Marraigang. As 
Marraigang and the Burra'gorang ran between the dry branches in the valley, Dharamuoy set the branches on fire, making the walls of the valley come alive with flames that spat contemptuously at the face of the Burra'gorang. As the Burra'gorang shied away from the flames, it suddenly found itself plummeting towards the ground as it tripped on the collapsing tunnels under its feet.

When it crashed to the ground, all the warriors used their diverse strengths to attack the Burra'gorang. Daruwa leaped in, digging its powerful teeth and claws underneath the segmented armour. Mun'dah slithered forward as the Burra'gorang's head struck the ground, and with blinding speed struck the monster's mouth, injecting more poison then she had ever mustered before. Wugatjin the Bull Art jumped into the very ear of the Burra'gorang, sinking its pincers into its nerves.

Despite these and other efforts from the warriors, the Burra'gorang began to lift its giant body, so Marraigang turned from his retreat and sank his sharp teeth into its gigantic tail. Yet the Burra'gorang thrashed violently thrash with its tail, crushing Marraigang against a nearby boulder and knocking Mananga from his flight, causing him to crash lifelessly into the valley walls. Although the warriors saw their bravest fall, they fought on.

It was then that a deep and powerful rumbling rolled through the valley as thunder clouds seemed to appear from nowhere, sending gusting winds screaming through the trees and sharp bolts of lightning crashing into the earth around the Burra'gorang. The Spirit Woman had arrived.

The powers that were suddenly unleashed between the Burra'gorang and the Spirit Woman shook the remaining warriors to their core, but they did not cower. Instead they sprung to the aid of the Spirit Woman, and after a day of non-stop fighting, where the valley was widened with immeasurable forces, new rivers cut into the earth, and hills shattered and recreated into great cliffs, the battle finally ended, and the Burra'gorang died.

The Spirit Woman looked down at the exhausted warriors, all of whom nursed their injuries. 'I thank you my true warriors, for I may not have defeated this beast without your help,' she said. She then carved the listless body of the Burra'gorang into many segments, and passed each segment to Elders from all the clans to be buried in many secret locations across the lands.

It was then she heard the weeping of Dharamuoy, who knelt over the bodies of Mananga and Marraigang. 'I am sorry that you have lost such fine warriors, but know that I will now carry their spirits with me back to my lands.' Before she left though, she stopped and pushed her hands into the earth and withdrew a gift. 'Dharamuoy, your use of fire helped trap the Burra'gorang, and for that I give you these rocks, the Worron, the Fire Rocks to help keep the clans warm.' And so, Dharamuoy became the keeper and the sharer of the fire for the D'harawal clans. 'May their warmth remind you all of our need to respect each other, and to share our stories.'

This is why, when strangers entered D'harawal lands, we did not threaten them. Instead we sat down with them by a fire, and sought to share our stories ... and learn from theirs. 


\section{REFLECTIVE QUESTION}

What are some examples today of government policy and practices that show a failure to listen to the voices of Aboriginal and Torres Strait Islander communities?

\section{Conclusion}

In this chapter we have attempted to reveal to readers the danger of not only ignoring the diversity of Aboriginal and Torres Strait Islander peoples today, but also their voices and stories. Through such ignorance, the foundations of our very communities are potentially threatened, as is the survival of our diverse cultures. Alongside these arguments, we have shared with you a traditional D'harawal Law Story. We do not claim ownership of this story, for our understanding, the meanings we assign to this story, belong to the Country on which it is told, what today is called the Burragorang Valley and adjoining Nattai Valley, in south-west Sydney. The version of the story that we have told is part of D'harawal Dreaming. We respect that other nations may also hold this story as part of their Dreamings, or similar versions of this story close to their hearts. We respect and appreciate the similarities and differences that can be found in our shared storylines and songlines that both directly and indirectly connect the D'harawal to many other Aboriginal nations. What we ask of you is to look into this story, and find its meaning for yourselves, and to understand that some of our traditional ways may still be alive today.

\section{Review exercises}

1 Consider the following in the contemporary context:

a Today, what could be symbolic of the Burra'gorang?

b How has today's Burra'gorang damaged Aboriginal and Torres Strait Islander peoples?

c How were the warriors able to fight the Burra'gorang?

d Why did it take so long for the Spirit Woman to answer the calls of the Elders?

2 What did the gift of the Worron (Fire Rocks) symbolise?

\section{References}

Bamblett, M., Harrison, J. \& Lewis, P. (2010). Proving culture and voice works: Towards creating the evidence base for resilient Aboriginal and Torres Strait Islander children in Australia. International Journal of Child and Family Welfare, 13, 98-113.

Baskin, C. (2005). Storytelling circles: Reflections of Aboriginal protocols in research. Canadian Social Work Review/Reuue canadienne de service social, 22(2), 171-87. 
Behrendt, L. Y. (2006). The urban Aboriginal landscape. In K. Anderson, R. Dobson, F. Allon \& B. Neilson (eds), After Sprawl: Post-Suburban Sydney. E-Proceedings of 'PostSuburban Sydney: The City in Transformation' Conference (pp. 1-8). Sydney: Centre for Cultural Research, University of Western Sydney.

Behrendt, L. Y. \& Kelly, L. (2008). Resolving Indigenous Disputes: Land Conflict and Beyond. Annandale, NSW: Federation Press.

Bessarab, D. \& Ng'andu, B. (2010). Yarning about yarning as a legitimate method in Indigenous research. International Journal of Critical Indigenous Studies, 3(1), 37-50.

Bodkin, F. (2013a). D'harawal Climate and Natural Resources. Sussex Inlet, NSW: Envirobook.

— (2013b). D'harawal: Dreaming Stories. Sussex Inlet, NSW: Envirobook.

Bodkin-Andrews, G. \& Carlson, B. (2016). The legacy of racism and Indigenous Australian identity within education. Race Ethnicity and Education, 19(4), 784-807.

Bodkin-Andrews, G. H., Denson, N. Finger, L. \& Craven, R. (2013). Identifying the fairy dust effect for Indigenous Australian students: Is positive psychology truly a [Peter] Pan-theory? In R. G. Craven, G. H. Bodkin-Andrews \& J. Mooney (eds.), International Advances in Education: Global Initiatives for Equity and Social Justice (pp. 183-210). Greenwich, CT: Information Age Publishing.

Carlson, B. (2013). The 'new frontier': Emergent Indigenous identities and social media. In M. Harris, M. Nakata \& B. Carlson (eds), The Politics of Identity: Emerging Indigeneity (pp. 147-68). Sydney: UTSePress.

Colquhoun, S. \& Dockery, A. M. (2012). The Link between Indigenous Culture and Wellbeing: Qualitative Evidence for Australian Aboriginal Peoples. Perth: Centre for Labour Market Research.

Cowlishaw, G. (2012). Culture and the absurd: The means and meanings of Aboriginal identity in the time of cultural revivalism. Journal of the Royal Anthropological Institute, 18(2), 397-417.

Dillon, A. (2013). No more victims. In R. Craven, A. Dillon \& N. Parbury (eds), In Black and White: Australians All at the Crossroads (pp. 75-90). Ballan, Vic.: Connor Court Publishing.

Dobia, B., Bodkin-Andrews, G., Parada, R., O’Rourke, V., Gilbert, S., Daley, A. \& Roffey, S. (2014). Aboriginal Girls Circle: Enhancing Connectedness and Promoting Resilience for Aboriginal Girls. Final Pilot Report. Penrith: University of Western Sydney

Dudgeon, P. \& Kelly, K. (2014). Contextual factors for research on psychological therapies for Aboriginal Australians. Australian Psychologist, 49(1), 8-13.

Everett, K. (2010). Urban Aboriginal ceremony: When seeing is not believing. In F. Peters-Little, A. Curthoys \& D. John (eds), Passionate Histories: Myth, Memory and Indigenous Australia (pp. 229-46). Canberra: ANU E Press. 
Foley, D. (2003). Indigenous epistemology and Indigenous standpoint theory. Social Alternatives, 22(1), 44-52.

Fredericks, B., Adams, K., Finlay, S., Fletcher, G., Andy, S., Briggs, L., Briggs, L. \& Hall, R. (2011). Engaging the practices of yarning in action research. ALAR Journal, 17(2), 7-19.

Gorringe, S., Ross, J. \& Fforde, C. (2011). 'Will the Real Aborigine Please Stand Up': Strategies for Breaking the Stereotype and Changing the Conversation. Canberra: Australian Institute of Aboriginal and Torres Strait Islander Studies.

Johns, G. (2011). Aboriginal Self-Determination: The Whiteman's Dream. Ballan, Vic.: Connor Court Publishing.

Kickett-Tucker, C. (2009). Moorn (Black)? Djardak (White)? How come I don't fit in Mum?: Exploring the racial identity of Australian Aboriginal children and youth. Health Sociology Review, 18(1), 119-36.

Kohen, J. (1993). The Darug and Their Neighbours: The Traditional Aboriginal Owners of the Sydney Region. Blacktown, NSW: Darug Link and the Blacktown and District Historical Society.

Kovach, M. (2009). Indigenous Methodologies: Characteristics, Conversations, and Contexts. Toronto: University of Toronto Press.

Linklater, R. (2014). Decolonizing Trauma Work: Indigenous Stories and Strategies. Halifax and Winnipeg: Fernwood Publishing.

McRae, D. (2006). The state of play. In N. Parbury \& R. G. Craven (eds.), Aboriginal Studies: Making the Connections (collected papers of the 12th National Aboriginal Studies Association Conference, 2-3 November 2006). Sydney: Aboriginal Studies Association.

Maddison, S. (2013). Indigenous identity, 'authenticity' and the structural violence of settler colonialism. Identities, 20(3), 288-303.

Martin, K. L. (2008). Please Knock Before You Enter: Aboriginal Regulation of Outsiders and the Implications for Researchers. Brisbane: Post Pressed.

Mercer, J., Kelman, I., Taranis, L. \& Suchet-Pearson, S. (2010). Framework for integrating Indigenous and scientific knowledge for disaster risk reduction. Disasters, 34(1), 214-39.

Moreton-Robinson, A. (2011). The white man's burden: Patriarchal white epistemic violence and Aboriginal women's knowledges within the academy. Australian Feminist Studies, 26(70), 413-31.

Nakata, M. (2012). Indigenous memory, forgetting and the archives. Archives and Manuscripts, 40(2), 98-105.

New South Wales Aboriginal Education Consultative Group (NSW AEGC). (2011). Aboriginality and Identity: Perspectives, Practices and Policy. Sydney: NSW AECG Inc. 
Price, D. \& Price, B. (2013). Good culture - bad culture. Where do we go from here? In R. Craven, A. Dillon \& N. Parbury (eds), In Black and White: Australians All at the Crossroads (pp. 191-208). Ballan, Vic.: Connor Court Publishing.

Purdie, N., Tripcony, P., Boulton-Lewis, G., Fanshawe, J. \& Gunstone, A. (2000). Positive Self-Identity for Indigenous Students and its Relationship to School Outcomes. Canberra: Commonwealth of Australia.

Rigney, L. I. (1999). Internationalization of an Indigenous anticolonial cultural critique of research methodologies: A guide to Indigenist research methodology and its principles. Wicazo sa review, 14(2), 109-21.

Riley, L. \& Genner, M. (2011). Bemel-Gardoo: Embedding cultural content in the science and technology syllabus. In N. Purdie, G. Milgate \& H. Bell (eds.), Two Way Teaching and Learning: Toward Culturally Reflective and Relevant Education (pp. 35-48). Camberwell, Vic.: ACER Press.

Rose, M. (2012). The 'silent apartheid' as the practitioner's blindspot. In K. Price (ed), Aboriginal and Torres Strait Islander Education: An Introduction for the Teaching Profession (pp. 64-79). Melbourne: Cambridge University Press.

Smith, L. T. (2012). Decolonizing Methodologies: Research and Indigenous Peoples. London and New York: Zed Books.

Trudgett, M. \& Page, S. (2014). When the Anths come marching in. The Australian Journal of Anthropology, 25(3), 388-90.

Walter, M. \& Andersen, C. (2013). Indigenous Statistics: A Quantitative Research Methodology. Walnut Creek, CA: Left Coast Press.

Wexler, L., White, J. \& Trainor, B. (2015). Why an alternative to suicide prevention gatekeeper training is needed for rural Indigenous communities: Presenting an empowering community storytelling approach. Critical Public Health, 25(2), 205-17.

Yamanouchi, Y. (2012). Managing 'Aboriginal selves' in south western Sydney. Oceania, 82(1), 62-73.

Zubrick, S. R., Silburn, S. R., Lawrence, D. M., Mitrou, F. G., Dalby, R. B., Blair, E. M, Griffin, J., Milroy, H., De Mino, J. A., Cox, A. \& Li, J. (2005). The Western Australian Aboriginal Child Health Survey: Forced Separation from Natural Family, Forced Relocation from Traditional Country or Homeland, and Social and Emotional Wellbeing of Aboriginal Children and Young People. Perth: Curtin University of Technology and Telethon Institute for Child Health Research. 